\title{
БИООРГАНИЧЕСКАЯ ХИМИЯ
}

DOI - 10.32743/UniChem.2021.84.6.11883

\section{ПОЛУЧЕНИЕ МЕТАЛЛОКОМПЛЕКСОВ ИОНОМ МЕДИ $\left(\mathrm{CU}^{2+}\right)$ С ПРОИЗВОДНЫМИ АМИНОКИСЛОТ}

Бекназаров Жахонгир Иззатуллоевич PhD, Нациинальный университет Узбекистана имени М. Улувбека, Республика Узбекистан, г. Ташкент E-mail: jahongir.beknazarov@mail.ru

Ибрагимов Азиз Бахтиёрович д-р хим. наук, Институт общей и неорганической химии АН Узбекистана, Республика Узбекистан, г. Ташкент

Болтаева Зебо Азатовна

мл. науч. сотр., Институт общей и неорганической химии АН Узбекистана,

Республика Узбекистан, г. Ташкент

Маулянов Салихжан Алимжанович кан. хим. наук, Национальный университет Узбекистана имени М. Улудбека,

Республика Узбекистан, г. Ташкент

Хаитбаев Алишер Хамидович

д-р хим. наук, проф. Нацุиональный университет Узбекистана имени М. Улудбека,

Республика Узбекистан, г. Ташкент

\section{PREPARATION OF METAL COMPLEXES COPPER ION (CU2+) WITH AMINO ACID DERIVATIVES}

Jahongir Beknazarov

PhD,

National University of Uzbekistan named after Mirzo Ulug'bek, Republic of Uzbekistan, Tashkent

Aziz Ibragimov

Doctor of Science, Institute of General and Inorganic Chemistry of AS, Uzbekistan, Republic of Uzbekistan, Tashkent

Zebo Boltayeva

Doctor of Science, Institute of General and Inorganic Chemistry of AS, Uzbekistan, Republic of Uzbekistan, Tashkent

Salixdjan Maulyanov

Candidate of Science National University of Uzbekistan named after Mirzo Ulug'bek, Republic of Uzbekistan, Tashkent

Alisher Haitbayev

National University of Uzbekistan named after Mirzo Ulug'bek, Republic of Uzbekistan, Tashkent

Библиографическое описание: Получение металлокомплексов ионом меди (Cu2+) с производными аминокислот // Universum: химия и биология : электрон. научн. журн. Бекназаров Ж.И. [и др.]. 2021. 6(84). URL: https://7universum.com/ru/nature/archive/item/11883 


\section{АННОТАЦИЯ}

В настоящее время значительно развивается медицинская фармакология под названием микроэлементология комплексных соединений на основе аминокислот, биогенных органических кислот и макро-, микроэлементов.

Это научное исследование также представляет собой информацию о производстве комплексов различных аминокислот с ионами металлов и изучении их свойств.

\section{ABSTRACT}

At the present time, medical pharmacology is developing significantly under the name of microelementology of complex compounds based on amino acids, biogenic organic acids and macro-, microelements.

This scientific research also provides information on the production of complexes of various amino acids with metal ions and the study of their properties.

Ключевые слово: аминокислота, глитцин, аланин, комплекс, 2,4-динитрофенил глицин, 2,4-динитрофенил$\alpha$-аланин, ИК сектр

Keywords: amino acid, glycine, alanine, complex, 2,4-dinitrophenyl glycine, 2,4-dinitrophenyl- $\alpha$-alanine, IRspectrum.

Аминокислоты как основные составные части белков участвуют во всех жизненных процессах наряду с нуклеиновыми кислотами, углеводами и липидами. При попадании в живой организм аминокислоты сразу же включаются в биохимические процессы [1].

Алифатические аминокислоты с линейными структурами - глицин, аланин и $\varepsilon$-аминокапроновая кислота имеют большое биологическое значение для человеческого организма. Глицину принадлежит важнейшая роль в деятельности мозга, поскольку глицин участвует в образовании важнейших биологически активных соединений (пуриновых нуклеотидов, гема, креатина и др). Глицин выполняет функцию тормозного нейромедиатора и контролирует процессы формирования тонкой моторики пластических процессов и тонусных реакций поперечнополосатой мускулатуры. Поэтому в неврологической практике глицин широко используется для устранения повышенного мышечного тонуса [2]. В организме человека основная масса глицина сконцентрирована в спинном мозге. Глицин является регулятором обмена веществ, нормализует и активирует процессы защитного торможения в центральной нервной системе. Глицин обладает адреноблокирующим, антиоксидантным и антитоксическим действием, за счет чего уменьшает психоэмоциональное напряжение, агрессивность, конфликтность, улучшает настроение, повышает социальную адаптацию; повышает умственную работоспособность; облегчает засыпание и нормализует сон; уменышает проявления вегетососудистых расстройств в целом и выраженность общемозговых расстройств при ишемическом инсульте и черепно-мозговых травмах; уменьшает токсическое действие алкоголя и других лекарственных средств, угнетающих функцию центральной нервной системы. Глицин является исходным материалом для синтеза обменных аминокислот в организме, а также донором аминогруппы при синтезе гемоглобина и других веществ. Наряду с другими аминокислотами глицин является частью полипептидной цепи, которая формирует первичную структуру всех белков [3].

Аминокислота $\beta$-аланин синтезируется в организме человека, поэтому не является незаменимой.
Биологическая роль $\beta$-аланина заключается в его участии в синтезе пантотеновой кислоты (витамина B5), которая необходима для синтеза ацилкоэнзима А. В свою очередь ацилкоэнзим А необходим для ферментов цикла карбоновых кислот (цикл Кребса) и жизненно необходим для синтеза основного субстрата энергетического метаболизма - аденозинтрифосфата АТФ. $\beta$-Аланин участвует нормализации терморегуляции и способствует стабилизации энергетического метаболизма за счет увеличения содержания пантотеновой кислоты, является важнейшим координатором фонда возбуждающих и тормозных нейромедиаторов, повышает дыхательную активность нейроцитов, ускоряет утилизацию глюкозы и улучшает кровообращение. $\beta$-аланин широко используется в медицинской практике для лечения мигреней, цереброваскулярной недостаточности и других заболеваний нервной системы, связанных с нарушением кровообращения $[1,3,4]$. В современной фармакологии интерес к аминокислотам биогенных металлов и их комплексным солям является актуальным.

Макро-, микроэлементы и жизненно важные минеральные элементы входят в генетический аппарат биологически активных веществ и клеток, а также они обеспечивают формирование различных органов и тканей. Сильное влияние макро- и микроэлементов на физиологические процессы можно объяснить тем, что они входят в состав ферментов и коферментов, участвующих в регуляции жизненно важных процессов.

Любое нарушение равновесия макро- и микроэлементов в организме зависит от коррекции, которая, в свою очередь, может произойти в результате применения определенных препаратов. Перспективные и биологически синтезируемые препараты этого класса могут включать биогенные металлы и аминокислотные лиганды, кислоты-метаболиты цикла Кребса, комплексные соединения, содержащие биологически активные органические кислоты.

Эффективность использования комплексных соединений биогенных металлов и аминокислот в качестве лекарственных средств в животноводстве $[5,6]$ и медицинской практике [7] достаточно освещена в литературе. 
Органически связанные макро- и микроэлементы с $\alpha$-аминокислотами (хелатами) обладают высокой биологической активностью, в котором они легче усваиваются организмом, чем неорганические соединения, имеют особое значение в качестве кормов для животных, а также широко используются в медицинской практике.

Аминокислотные хелаты макро- и микроэлементов являются единственным видом продукта, который отвечает требованиям биологически активных препаратов для восполнения количества микроэлементов в организме.
Обсуждение полученных результатов

На основании приведенных данных мы синтезировали металлический комплекс $\mathrm{Cu}^{2+}$ с производным глицина - 2,4-динитрофенил глицином.

Для определения кристалличности реагентов и продуктов реакции провели рентгенофазовый анализ с помощью прибора XRD -6100 (X-Ray Diffractometer) Данные полученные по кристалличности 2,4-динитрофенил глицина приведены в следующем 1-рисунке:

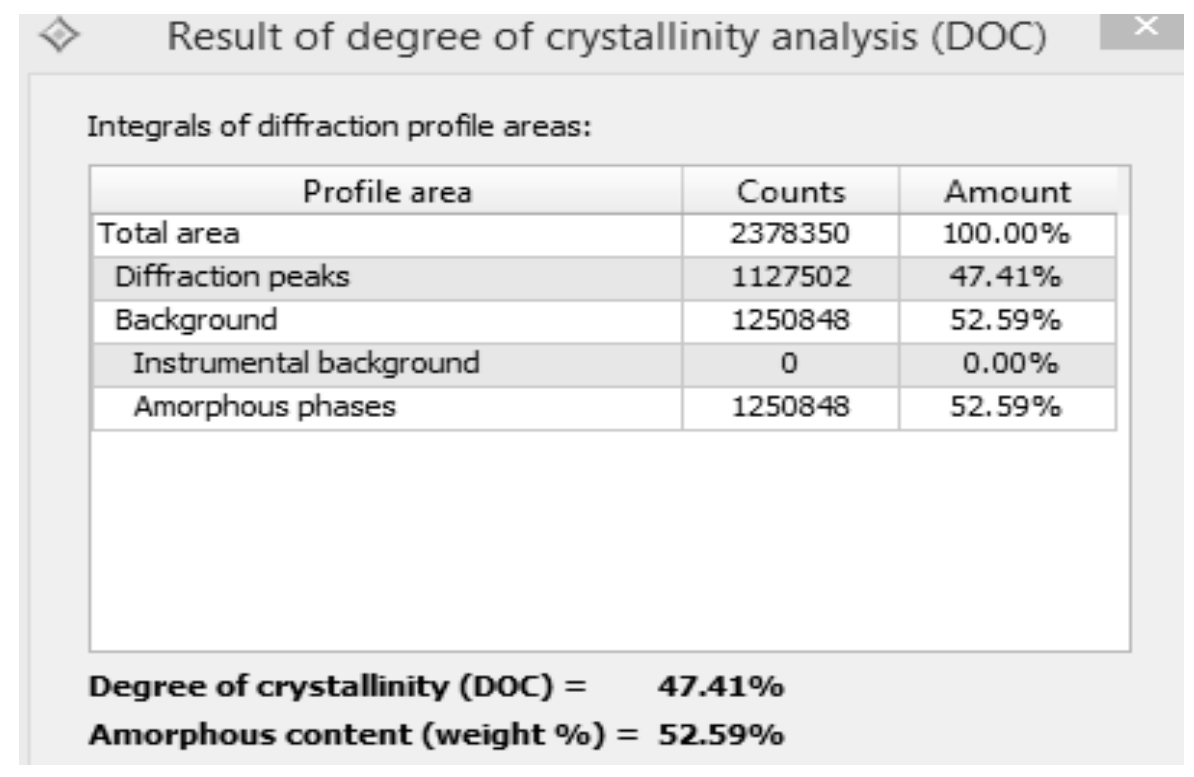

Рисунок 1. Данные кристалличности 2,4-динитрофенил глицин (реагент)а

Реакцию проводили при $40^{\circ} \mathrm{C}$ и $\mathrm{pH}=9$ в течение 4 часов. Реакцию можно изобразит следующей схемой:

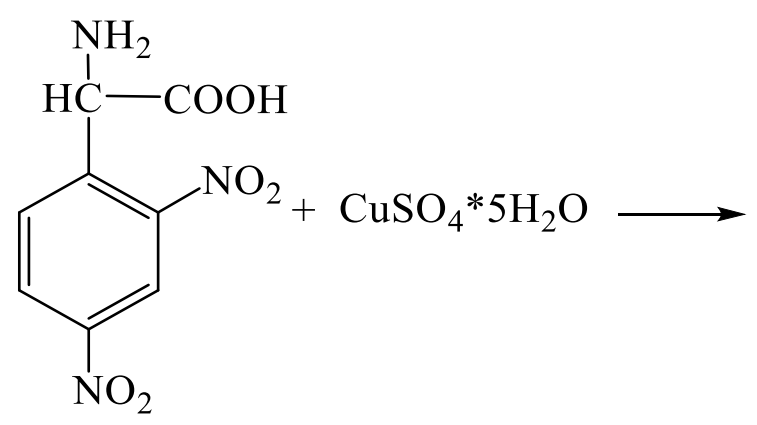

Данные полученные по кристалличности полученного продукта реакции 2,4-динитрофенил<smiles></smiles>

глицина с ионами $\mathbf{C u}^{2+}$ приведены в следующем 2-рисунке: 


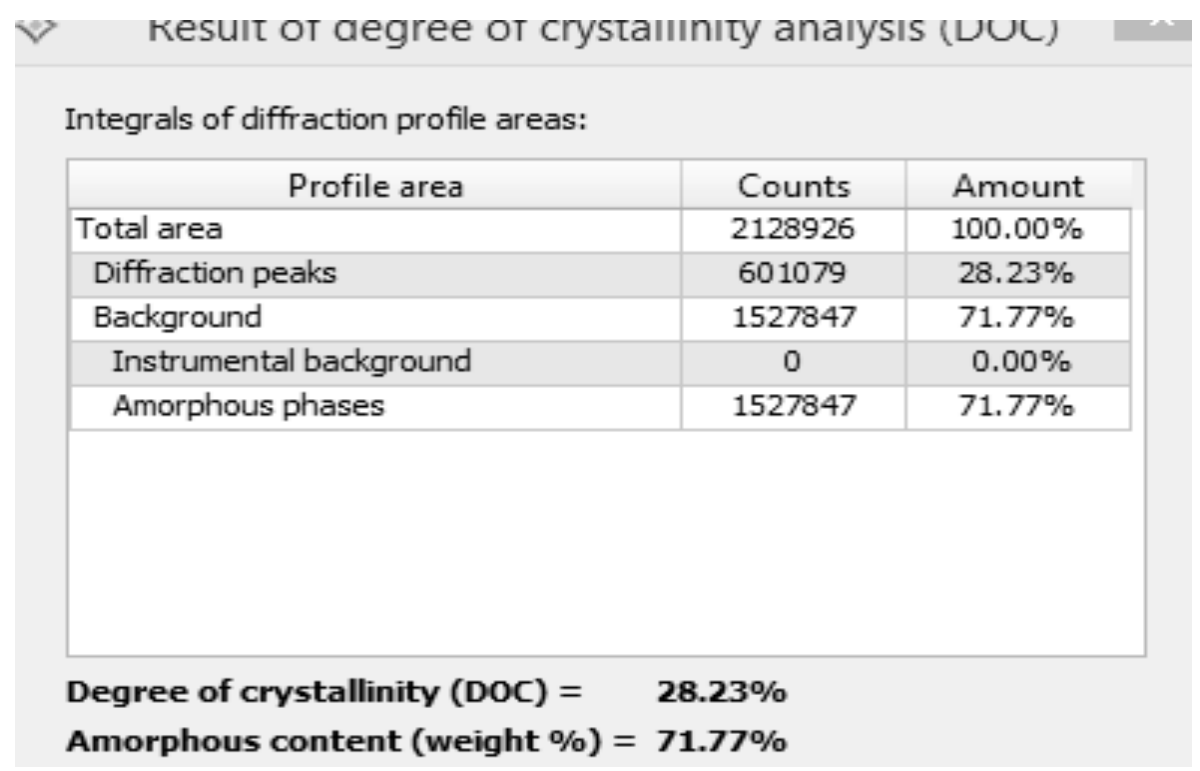

Рисунок 2. Данные кристалличности продукта реакции 2,4-динитрофенил глицина с ионами Сй

Также, для проверки хода реакции сняли ИК-спектр полученных продуктов. Полученные результаты приведены в 3-рисунке.

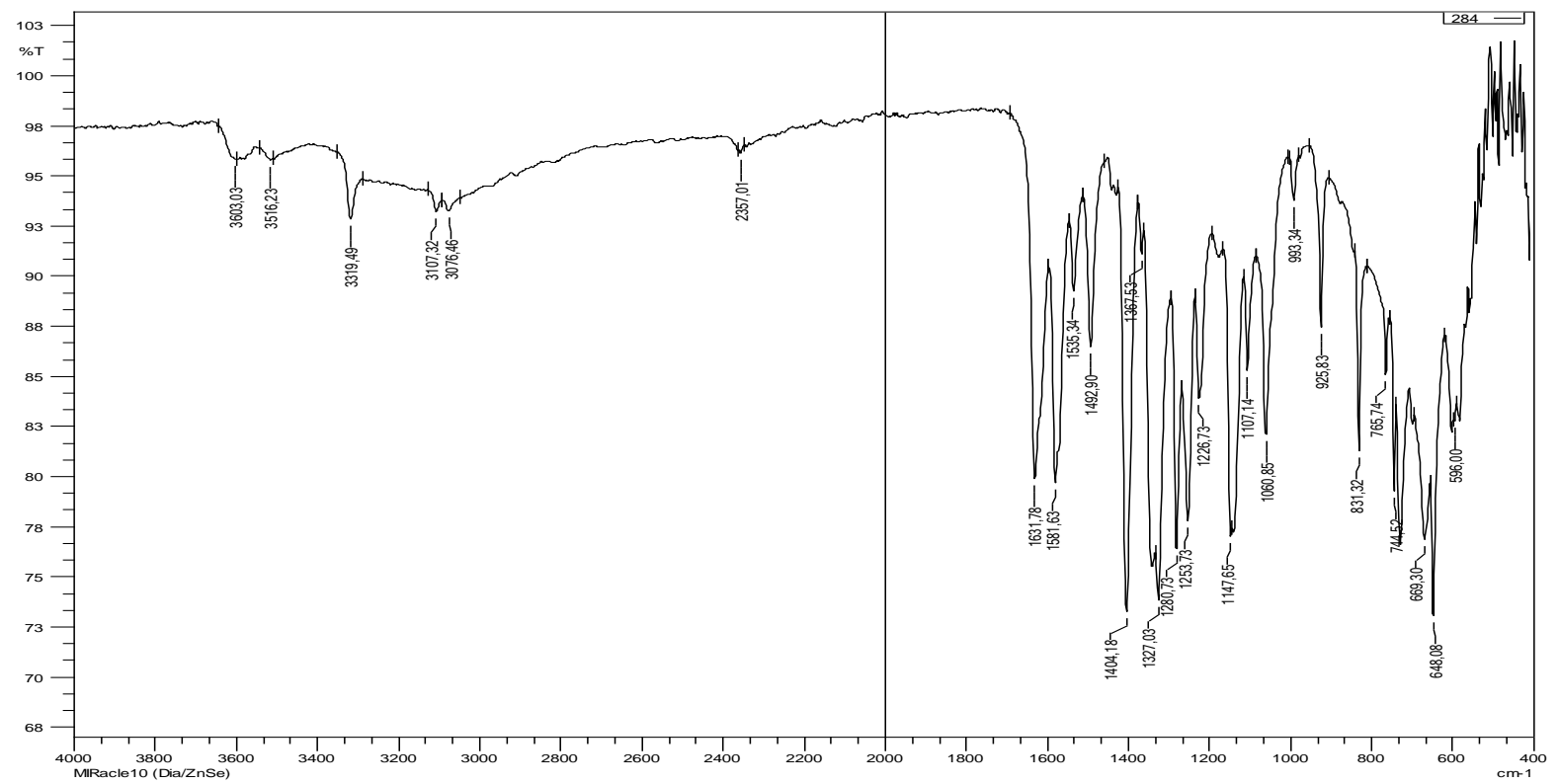

Рисунок 3. ИК-спектр комплекса 2,4-динитрофенилглицина с $\mathrm{Cu}^{2+}$

Исследования проводились в спектрометре MIRacle10 (Dia/ZnSe). В ИК-спектре комплексного соединения 2,4-динитрофенил глицина с купоросом меди можно увидеть резкие различия чем в ИКспектре самого 2,4-динитрофенил глицина. В частности, колебательная частота в области $1712 \mathrm{~cm}^{-1}$, принадлежащий связи С-О карбоксильной группы 2,4-динитрофенил глицина, исчез в комплексном спектре, интенсивность линии поглощения $\mathrm{OH}^{-}$группы в области $3352 \mathrm{~cm}^{-1}$ уменьшалась в комплексном спектре и перемещалась до области $3319 \mathrm{~cm}^{-1}$. Также было замечено, что интенсивность линий поглощения группы $-\mathrm{NO}_{2}$ в ИК-спектре 2,4-динитрофенил глицина в области 1521-1496 см с-1 $^{-14 \% а л а с ь ~ и ~}$ сдвигалась до области 1535-1492 см-1. В области $596 \mathrm{~cm}^{-1}$ наблюдались колебания новой $\mathrm{Cu}-\mathrm{O}$ связи. Из ИК-спектра комплексного продукта можно сделать вывод, что Сu связана с атомами кислорода карбоксильной группы в аминокислоте посредством наличия ковалентных связей.

Для определения кристалличности реагентов и продуктов реакции провели рентгенофазовый анализ. Данные полученные по кристалличности 2,4-динитрофенилаланина приведены в следующем 4-рисунке: 


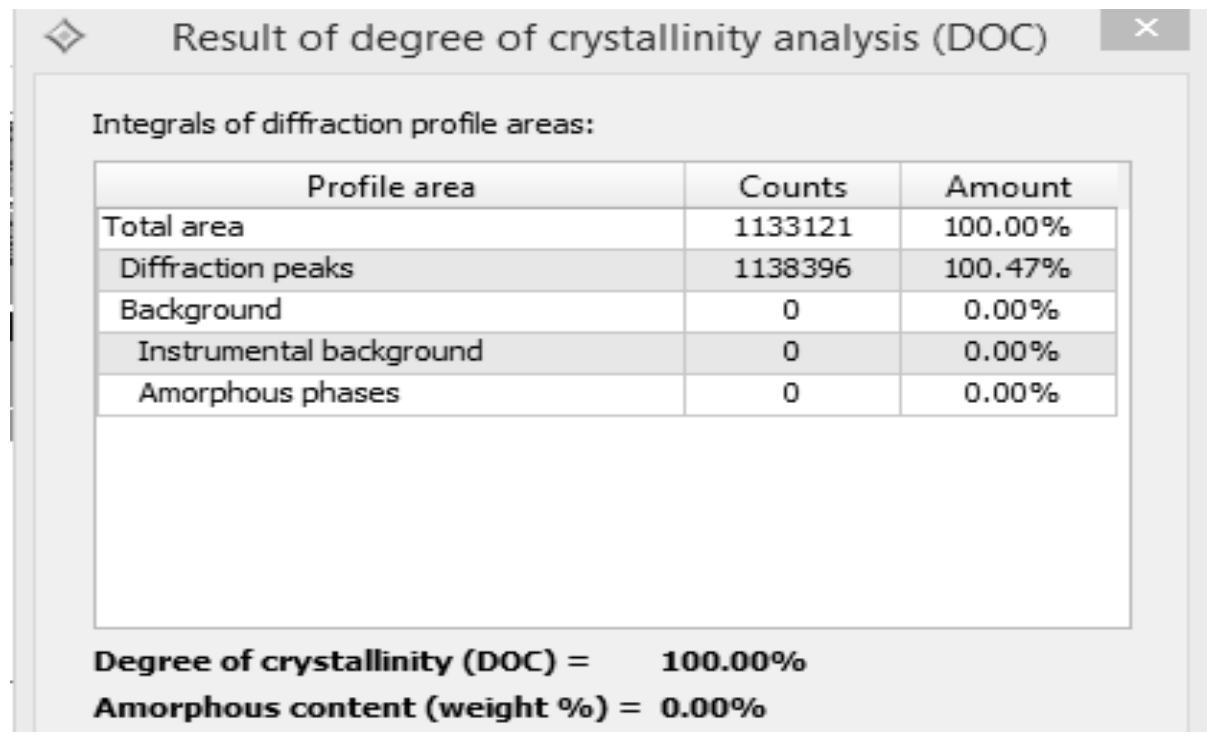

Рисунок 4. Данные кристалличности 2,4-динитрофенил аланин (реагент)а

Реакцию проводили при $40^{\circ} \mathrm{C}$ и $\mathrm{pH}=9$ в течение 4 часов. Реакцию можно изобразит следующей схемой:

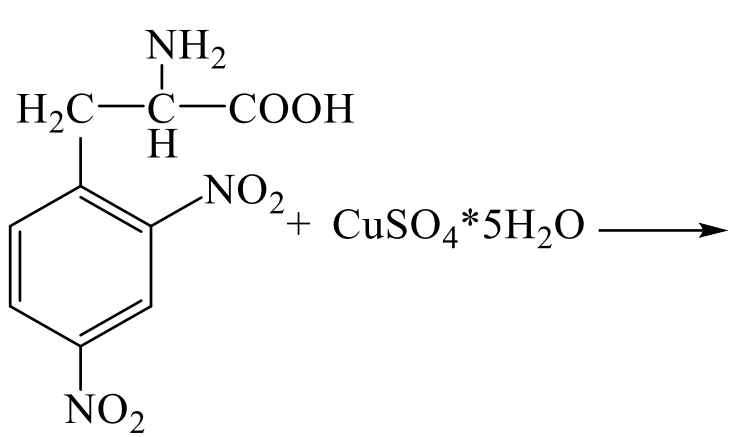

Данные полученные по кристалличности полученного продукта реакции 2,4-динитрофенил

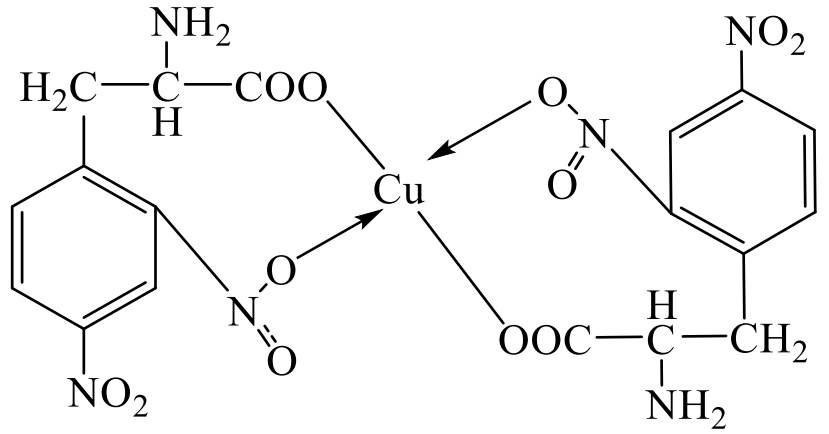

аланина с ионами $\mathrm{Cu}^{2+}$ приведены в следующем 5-рисунке:

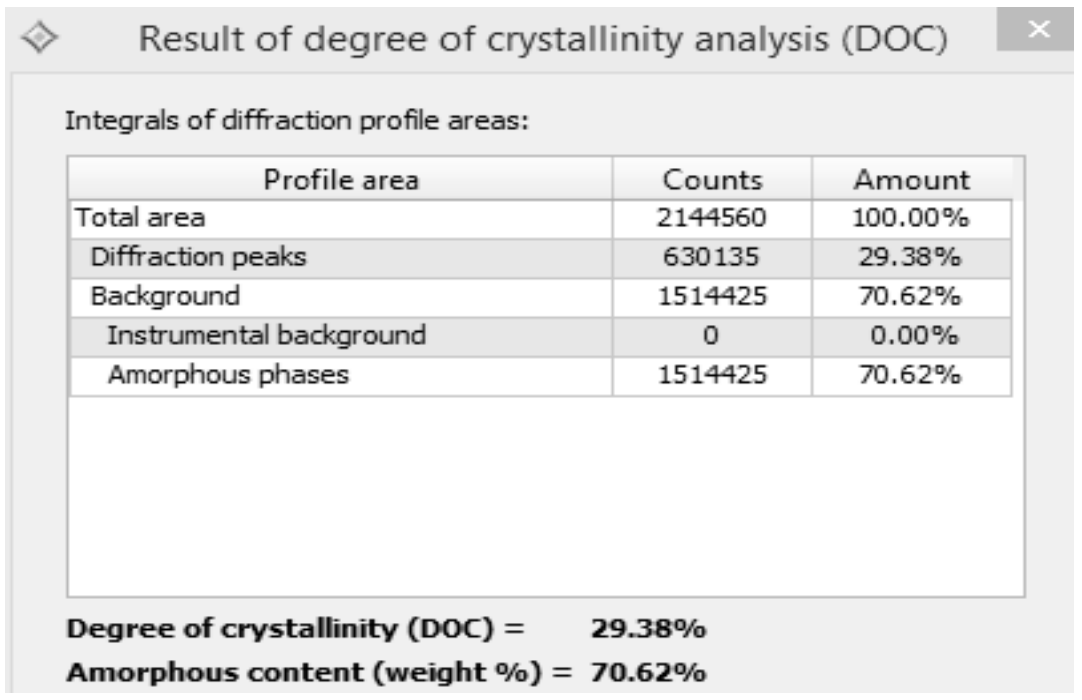

Риснок 5. Данные кристалличности продукта реакции 2,4-динитрофенил аланина с ионами Си ${ }^{2+}$

Также, для проверки хода реакции сняли ИКспектр полученных продуктов. Полученные результаты приведены в 6-рисунке. 


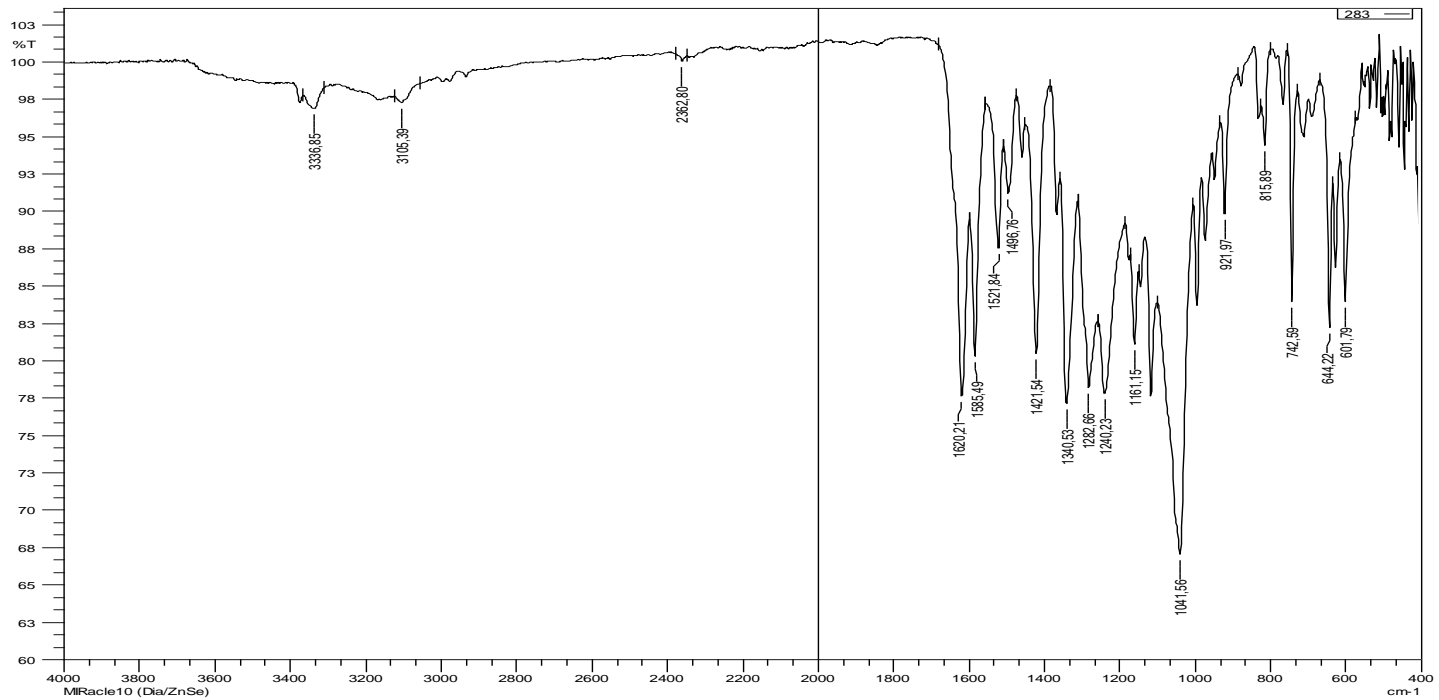

Рисунок 6. ИК-спектр комплекса 2,4-динитрофенилаланина с Сü

В ИК-спектре комплексного соединения 2,4 -динитрофенил- $\alpha$-аланина с купоросом меди можно увидеть резкие различия чем в ИК-спектре самого 2,4-динитрофенил- $\alpha$-аланина. В частности, колебание карбоксильной группы 2,4-динитрофенил$\alpha$-аланина в связи $\mathrm{C}=\mathrm{O}$ исчез в комплексном спектре в области $1705 \mathrm{~cm}^{-1}$, а интенсивность линии поглощения группы $\mathrm{OH}^{-}$в области $3315 \mathrm{~cm}^{-1}$ тоже исчез в комплексном спектре. Также снизилась интенсивность линий поглощения группы $-\mathrm{NO}_{2}$ в ИК-спектре 2,4-динитрофенил глицина в области 1521-1496 см1. В области $602 \mathrm{~cm}^{-1}$ наблюдались колебания новой связи $\mathrm{Cu}-\mathrm{O}$. Из ИК-спектра комплексного продукта можно сделать вывод, что $\mathrm{Cu}$ связана с атомами кислорода карбоксильной группы в аминокислоте посредством наличия ковалентных связей.

\section{Экспериментальная часть}

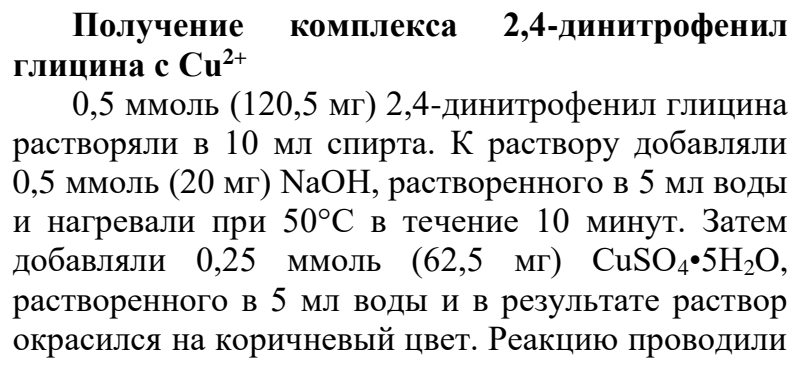

при $50^{\circ} \mathrm{C}$ путем перемешивания в течение 4 часов с использованием магнитной мешалки.

Получение комплекса

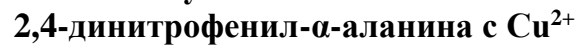

0,5 ммоль (127,5 мг) 2,4-динитрофенил- $\alpha$-аланина растворяли в 10 мл спирта. К раствору добавляли 0,5 ммоль (20 г) $\mathrm{NaOH}$, растворенного в 5 мл воды и нагревали при $50^{\circ} \mathrm{C}$ в течение 10 минут. Затем добавляли 0,25 ммоль $\left(62,5\right.$ мг) $\mathrm{CuSO}_{4} \cdot 5 \mathrm{H}_{2} \mathrm{O}$, растворенного в 5 мл воды и в результате раствор окрасился на коричневый цвет. Реакцию проводили при $50^{\circ} \mathrm{C}$ путем перемешивания в течение 4 часов с использованием магнитной мешалки.

\section{Заключение}

1) Полученные данные рентгенофазового анализа (прибором XRD -6100 (X-Ray Diffractometer)) показывают значительные отличия данных кристалличности реагентов и продуктов реакций.

2) Полученные данные ИК-спектроскопии доказывают о получении металлокомплексов ионов меди $\left(\mathrm{Cu}^{2+}\right)$ с производными аминокислот.

3) Синтезированные металлокомплексы ионов меди $\left(\mathrm{Cu}^{2+}\right)$ с производными аминокислот переданы для изучения биологической активности.

\section{Список летературы:}

1. Нельсон Д., Кокс М. Основы биохимии Ленинджера.В 3-х томах. Т.1. - М.: БИНОМ. Лаборатория знаний, 2012. -694 c.

2. Белобородов В.Л. Органическая химия. - М.: Дрофа, 2004. -599 с.

3. Белоусов Ю.Б., Кукес В.Г., Лепахин В.К., Петров В.И. Клиническая фармакология: национальное руководство. М.: ГЭОТАР-Мед. 2014. -976 c.

4. Ерпулёва Ю.В. // Журнал Лечащий врач. - 2013. - № 3 - С. 51-54.

5. Кабиров Г.Ф. Разработка средств профилактики и лечения гипомикроэлементозов овец и свиней: Дис. докт. вет. наук. -Казань, 2000. - 317 с.

6. Кабиров Г.Ф. Хелатные формы биогенных металлов в животноводстве / Г.Ф. Кабиров, Г.П. Логинов, Н.3. Хазипов. -Казань: ФГОУ ВПО КГАВМ, 2004. - 284 с.

7. Машковский М.Д. Лекарственные средства. Т.2. - М.: Новая волна, 2000. - С. 441. 